Jefferys, E. G. (1952). J. gen. Microbiol. 7, 295-312.

\title{
The Stability of Antibiotics in Soils
}

\author{
BY E. G. JEFFERYS \\ Imperial Chemical Industries Ltd., Butterwick Research Laboratories, \\ Welwyn, Hertfordshire
}

\begin{abstract}
SUMMARY: Ten antibiotics have been included in this study; eight of them were metabolic products of fungi isolated from soils of the Bagshot Sand type. Their stability in Bagshot Sand soils and in a neutral garden loam has been investigated. Some were more stable than others, the rate of inactivation varied from soil to soil, but all exhibited a fair degree of stability in some of the soils. Four types of inactivation could be distinguished: (1) The natural $\mathrm{pH}$ of the soil was sometimes that at which the antibiotic was intrinsically unstable; this was noted specially with albidin, frequentin, gliotoxin, penicillin and viridin. (2) Inactivation caused by some form of biological activity, indicated by less rapid inactivation in heattreated than in untreated soil, was observed with griseofulvin, mycophenolic acid and patulin. (3) Adsorption on the soil was noticeable only in the case of streptomycin, the only basic antibiotic studied; acid-washed sand was able to bind appreciable quantities of this antibiotic. (4) Some other form of inactivation, probably chemical in nature, was concerned in the inactivation of gladiolic acid, penicillin and streptomycin.
\end{abstract}

Discussion of the natural significance of antibiotics logically follows the discovery of their production by micro-organisms. Similarly, consideration of their possible role in soil ecology follows from the fact that many soil micro-organisms are capable of producing them. Prerequisites of a balanced judgement on the subject include information on: $(a)$ the types of microorganism commonly isolated from various types of soil; $(b)$ the antibiotics produced by such soil micro-organisms; $(c)$ the stability of such antibiotics in the soil from which their producers were isolated; $(d)$ the mode of inactivation of these antibiotics where this is found to occur; $(e)$ the possibilities of detecting antibiotic production and accumulation in natural soils; (f) competition between strains of micro-organisms which do and do not produce antibiotics; $(g)$ the significance-if any - of antibiotics to the microorganisms which produce them.

The present paper is concerned with the stability and mode of inactivation of antibiotics in soil. In order to relate this as closely as possible to conditions under which antibiotics might naturally be produced, the majority of the antibiotics chosen for study were produced by fungi isolated from the Bagshot Sand type of soil, in which production of antibiotics under natural conditions has been suspected (Brian, Hemming \& McGowan, 1945; Rayner, 1945). Furthermore, among the soils selected for study were soils from different levels of a Bagshot Sand soil profile. Streptomycin has been included, although actinomycetes in general are scarce in these acid soils, to afford a basis of comparison with the somewhat similar studies of Siminoff \& Gottlieb (1951) and Pramer \& Starkey (1951). 


\section{MA'TERIALS}

Soils. Four of the soils used were obtained from the profile of a pit dug in a typical Bagshot Sand podsol on Wareham Heath, Dorset. The fifth sample, included for comparison, was a neutral light garden soil from Welwyn, Hertfordshire. The origin and properties of these soils are shown in Table 1.

Table 1. Description of soils used

\begin{tabular}{|c|c|c|c|c|c|}
\hline \multirow[b]{2}{*}{ Sample } & \multicolumn{3}{|r|}{ 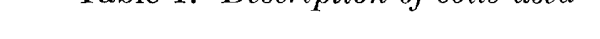 } & \multicolumn{2}{|c|}{$\mathrm{pH}$ value } \\
\hline & Horizon & (in.) & Description & Fresh & Sterile \\
\hline \multicolumn{6}{|c|}{ Soils from profile from Wareham Heath, Dorset } \\
\hline$*$ & $\mathbf{A}_{0}$ & $0-2$ & Litter and peat & - & 一 \\
\hline Wareham I & $A_{1}$ & $2-6$ & Black sandy peat & $4 \cdot 2$ & $4 \cdot 1$ \\
\hline$*$ & $A_{2}$ & $6-10$ & $\begin{array}{l}\text { Slightly leached grey } \\
\text { sand }\end{array}$ & - & - \\
\hline Wareham II & $\mathbf{A}_{3}$ & $10-18$ & Leached sand & $5 \cdot 0$ & $5 \cdot 4$ \\
\hline Wareham III & $\mathrm{B}_{1-2}$ & $18-22$ & Podsol pan & $4 \cdot 2$ & $4 \cdot 3$ \\
\hline Wareham IV & $\mathrm{C}^{1-2}$ & $22-26$ & $\begin{array}{l}\text { Brown sandy gravel-- } \\
\text { some clay }\end{array}$ & $4 \cdot 9$ & $5 \cdot 0$ \\
\hline \multicolumn{6}{|c|}{ Soil from Laboratory Garden, Welwyn, Hertfordshire } \\
\hline Garden & - & $0-3$ & Light neutral loam & $7 \cdot 2$ & $7 \cdot 2$ \\
\hline
\end{tabular}

After collection the soils were air-dried, coarsely crushed and stored in tins at room temperature. The sand used in some experiments was washed for $24 \mathrm{hr}$. in running water, then for $12 \mathrm{hr}$. in $c$. $\mathrm{N}-\mathrm{HCl}$, and finally for another $36 \mathrm{hr}$. in running water. After this treatment very little clay remained and it had virtually no buffering capacity. Assays made as later described on aqueous extracts of these soils, at the concentration used in the experiments, showed no antifungal or antibacterial activity. Thus, all activity measured in the experiment can only have been caused by the antibiotic added.

Antibiotics. The following antibiotics were studied: albidin (Curtis \& Grove, 1947), frequentin (Curtis, Hemming \& Smith, 1951), gladiolic acid (Brian, Curtis \& Hemming, 1948), gliotoxin (Brian, 1946), griseofulvin (Brian, Curtis \& Hemming, 1946), mycophenolic acid, patulin, viridin (Brian \& McGowan, 1945), penicillin and streptomycin. All these, except the last two, were prepared in these laboratories from fungi isolated from soils of the Bagshot sand type. These organisms are listed in Table 2.

Frequentin, patulin, penicillin and streptomycin are soluble in cold water, so that solutions of the required concentration could easily be prepared. The remaining antibiotics being only sparingly soluble in water are most conveniently brought into solution in a small quantity of a water-miscible organic solvent followed by dilution with water. To complicate the interpretation of results by the introduction of organic solvents into the system was undesirable, as these might well alter the microbiological activity of soil, so this method was not used. Gladiolic acid and mycophenolic acid were obtained as aqueous solutions of their sodium salts by solution in sodium 
hydroxide of appropriate strength. Gliotoxin and viridin were unstable in simple aqueous solution and were prepared in a dilute McIlvaine buffer by refluxing in a citric acid solution of appropriate strength, and adding the phosphate of the buffer in appropriate quantities later. Albidin was dissolved in the cold in water slightly acidified with $\mathrm{HCl}$. Griseofulvin was dissolved by refluxing in water. The concentration of griseofulvin, viridin and albidin solutions was determined, after preparation of the solutions, by biological assay.

Table 2. Origin, potency and method of assay of antibiotics

\begin{tabular}{|c|c|c|c|}
\hline Antibiotic & Produced from & Potency & Assay \\
\hline Albidin & Penicillium albidum Sopp (BRL 248) & $0 \cdot 6$ & BA \\
\hline Frequentin & P. frequentans Westl. (BRL737) & $3 \cdot 0$ & BA \\
\hline Gladiolic acid & $\begin{array}{l}\text { P. gladioli MeCull \& Thom } \\
\text { (BRL 59) }\end{array}$ & $7 \cdot 0$ & $\mathbf{B A}$ \\
\hline Gliotoxin & $\begin{array}{l}\text { P. terlikowskii Zal. (BRL 536) } \\
\text { Trichoderma viride Pers. ex Fr. } \\
\quad \text { (BRL 211) }\end{array}$ & $3 \cdot 5$ & $\mathbf{B A}$ \\
\hline Griseofulvin & $\begin{array}{l}P . \text { nigricans (Bainier) Thom } \\
\quad(\text { BRL 250) }\end{array}$ & $1 \cdot 1$ & $\mathbf{B A}$ \\
\hline Mycophenolic acid & P. stoloniferum Thom (BRL438) & $0 \cdot 4$ & $\mathbf{B A}$ \\
\hline Patulin & P. expansum Link (BRL 440) & 一 & SCP \\
\hline Viridin & $\begin{array}{l}\text { Trichoderma viride Pers. ex Fr. } \\
\quad \text { (BRL 213) }\end{array}$ & $0 \cdot 06$ & BA \\
\hline Penicillin & P. chrysogenum Thom & 1690 units/mg. & SCP \\
\hline Streptomycin & $\begin{array}{l}\text { Streptomyces griseus (Krainsky) } \\
\text { Waksman \& Henrici }\end{array}$ & 423 units/mg. & SCP \\
\hline
\end{tabular}

Notes. The numbers appearing in parentheses after names of organisms are the accession numbers in the culture collection of Butterwick Research Laboratories (BRL). Penicillin G was supplied by I.C. Pharmaceuticals Ltd. Streptomycin was supplied by Boots Pure Drug Co. Ltd. Potencies refer (except in the case of streptomycin and penicillin) to least concentrations $(\mu \mathrm{g} . / \mathrm{ml}$.) preventing germination of Botrytis allii spores or (in case of griseofulvin) producing curling of Botrytis allii hyphae. Methods of assay: $\mathbf{B A}=$ Botrytis allii spore germination test; $\mathbf{S C P}=$ Bacillus subtilis cylinder plate assay.

\section{METHODS}

Experimental layout. The stability of each antibiotic in a McIlvaine buffer $\left(0.01 \mathrm{M}\right.$-citric acid $\left.+0.02 \mathrm{M}-\mathrm{Na}_{2} \mathrm{HPO}_{4}\right)$ over a $\mathrm{pH}$ range of $3-7$ was first determined. Next, the stability of similar solutions was determined in the presence of acid-washed sand. Finally, the stability of solutions of the antibiotic was determined in the presence of each of the five soils previously described, using both air-dried but otherwise untreated soil (subsequently referred to as fresh) and soil autoclaved at $15 \mathrm{lb} . / \mathrm{sq}$. in. for $25 \mathrm{~min}$. (subsequently referred to as partially sterile). In most cases both water solutions and buffer solutions of the antibiotic were exposed to fresh soil, the buffer being of a $\mathrm{pH}$ value close to the natural $\mathrm{pH}$ value of the soil; buffer solutions only were exposed to partially sterile sand and soil. For reasons already explained experiments with viridin and gliotoxin could only be carried out in buffer. Since the buffers 
used were very dilute, the $\mathrm{pH}$ value occasionally drifted slightly during the course of the experiment.

In the soil and sand experiments $250 \mathrm{ml}$. antibiotic solution was placed in a 'Glaxo' culture vessel and $25 \mathrm{~g}$. (air-dry weight) of soil added. This gave a $2 \mathrm{~mm}$. layer of soil or sand with a $10 \mathrm{~mm}$. supernatant layer of solution. It is appreciated that such conditions might seem to be unduly anaerobic and that an excessive proportion of antibiotic solution was exposed to a given volume of soil. It was thought, however, that under such conditions processes of inactivation would be slowed down and more readily studied. Moreover, preliminary experiments in which this condition was compared with the more obviously aerobic conditions of a soil percolator (Jefferys \& Smith, 1951), indicated that there was little difference between the two experimental conditions. The static technique, being far simpler to handle, was therefore adopted.

In all experiments two concentrations of antibiotic were used. The lower was the lowest that could be conveniently assayed and the higher was in all cases ten times greater than the lower.

Methods of assay. Samples for assay were aseptically taken and every effort was made to remove at the same time a part of the soil present, in order to maintain an approximately constant ratio between soil and solution. Assays were made within $\mathrm{l} \mathrm{hr}$. of setting up the experiment and thereafter at suitable intervals. All samples were filtered through No. 5 Whatman filter-paper before assay.

Patulin, penicillin and streptomycin were assayed by the cylinder plate technique (Foster \& Woodruff, 1944). The test organism in each case was Bacillus subtilis, a strain received from I.C. Pharmaceuticals Ltd. being used for assay of patulin and penicillin, and a strain (NCTC 7241) obtained from Boot's Pure Drug Co. Ltd. for streptomycin. The assay agar contained peptone, Lab-Lemco meat extract and Marmite. Standard curves were constructed daily and the concentrations of the antibiotics in the unknown solutions estimated graphically from these curves.

The remaining antibiotics were assayed by a serial dilution spore germination test using conidia of Botrytis allii. Brian \& Hemming (1945), describing the method, used the inhibition of germination as the end-point of the assay. In the present work, the end-point used was based on loss of the germ tubes, which occurs at higher dilutions than inhibition of spore germination. This results in a more sensitive assay. Titres are expressed in 'dilution units'. This term is the number of consecutive twofold dilutions, through which inhibition of germination or stunting of germ-tubes can be recognized. These units are proportional to the logarithm of the concentration of the active material.

The assay of griseofulvin is different in that the limiting concentrations needed to produce the various characteristic morphological changes in germ-tubes were recorded; results are presented similarly in dilution units. 


\section{RESULTS}

These are expressed in Figs. 1-19, and commented on in the text below.

\section{Albidin}

Albidin is unstable throughout the range $\mathrm{pH} 3 \cdot 3-6 \cdot 9$ in buffer solution (Fig. 1). In the more acid solution ( $\mathrm{pH} 3 \cdot 3-4 \cdot 8$ ), after an initial rapid fall in activity, a steady level of activity is reached. This can be interpreted as meaning that albidin breaks down to a second antifungally active material of greater stability at low pH. At pH 5.9 and above, the active degradation product is also unstable. Sand had little effect on the rate of inactivation of albidin. The soils varied in their effect (Fig. 2). Wareham II and IV had little effect. In Wareham I, and less noticeably in Wareham III, the rate of inactivation in fresh soil is greater than would be expected merely from the $\mathrm{pH}$ of the solution, though partially sterile soil had little effect. This can best be interpreted as due to microbial activity; such differential inactivation in fresh and partially sterile soil is termed 'biological inactivation' in the following pages. In the garden soil inactivation is extremely rapid, as would be expected from the high $\mathrm{pH}$; indications of biological inactivation are slight.

\section{Frequentin}

Buffer solutions of frequentin (Fig. 3) are highly stable in the range $\mathrm{pH}$ 3.3-4.6. Activity is slowly lost at $\mathrm{pH} 5 \cdot 7$ and more rapidly at $\mathrm{pH} 6 \cdot \mathbf{9}$. Sand has no effect on the rate of inactivation at neutrality, but at lower $\mathrm{pH}$ it may somewhat increase the rate of inactivation (Fig. 3). The rate of inactivation in Wareham II and IV soils (Fig. 4) is similar to that in buffer or in buffer and sand. In Wareham I and III soils inactivation is more rapid, and in Wareham I the greater rate of inactivation in fresh soil as compared with the rate in partially sterile soil, suggests that here again biological inactivation is taking place. Inactivation is very rapid in garden soil; this is mainly attributable to the high $\mathrm{pH}$, but there is some indication of biological inactivation in the fresh soil.

\section{Gladiolic acid}

Gladiolic acid solutions in buffer (Fig. 5) are fairly stable in the range pH 3.4-7.0 and addition of sand has no effect. Once again Wareham II and IV soils had no effect. Inactivation at a much greater rate takes place in Wareham I and III and garden soils (Fig. 6); the rate of inactivation is little greater in fresh than in partially sterile soil. This indicates that in these soils inactivation is mainly due to some cause other than microbial decomposition or inactivation attributable to $\mathrm{pH}$.

\section{Gliotoxin}

Buffer solutions of gliotoxin (Fig. 7) are highly stable at $\mathrm{pH} \mathbf{3 . 4}$ and $\mathbf{4 . 9}$. Above pH 4.9 slow inactivation takes place, being more rapid the higher the $\mathrm{pH}$. Sand had little if any effect on the rate of inactivation. In the presence of all the soils such inactivation as was observed (Fig. 8) could be explained by the $\mathrm{pH}$ of the system. 

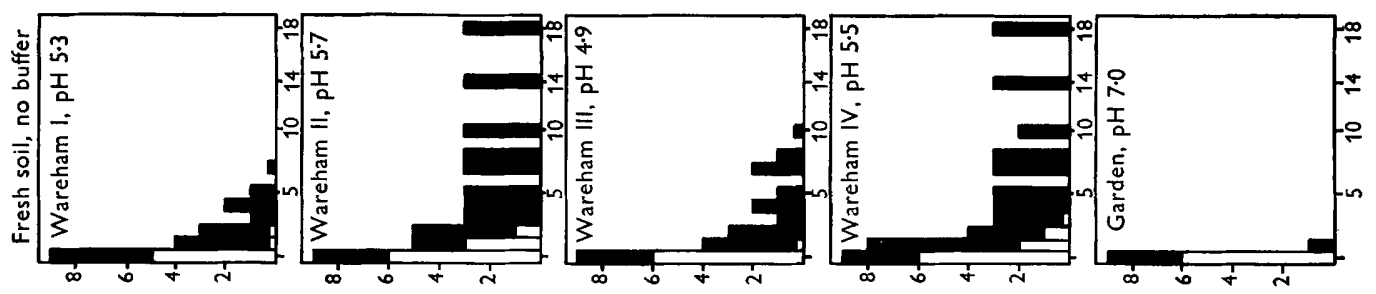

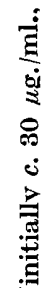
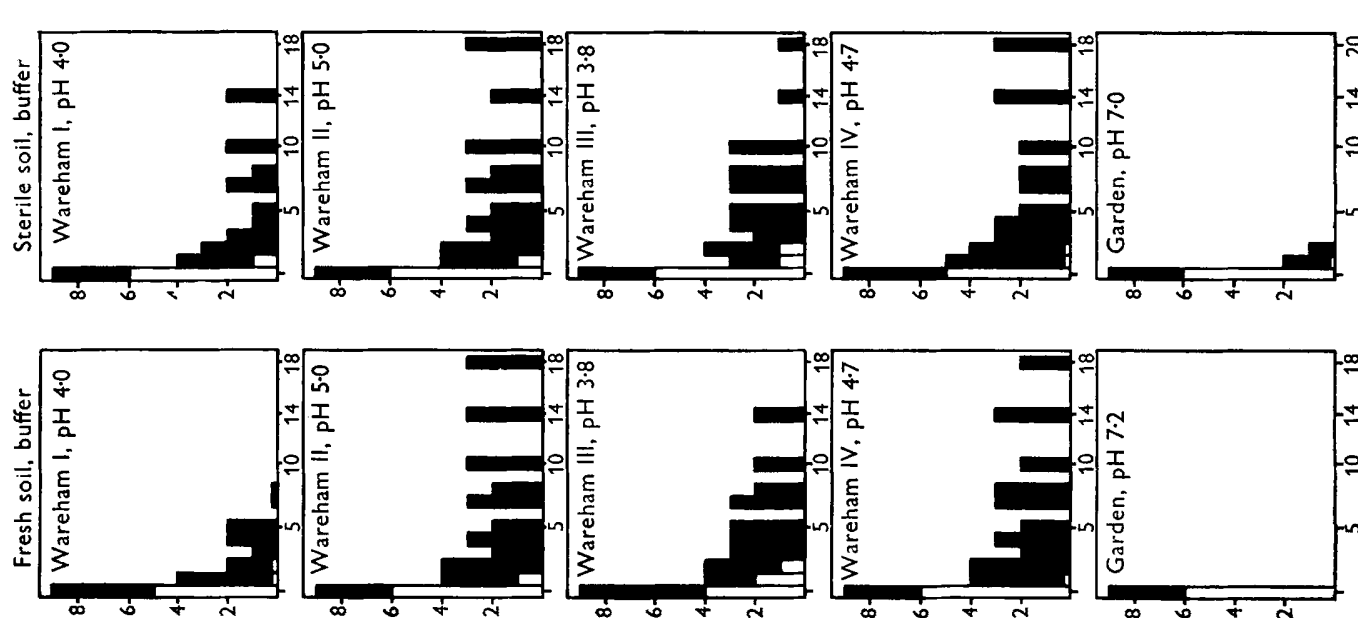

słlun . Uo! $2 n ! ! P . ~ U ! ~ ว .17 ! \perp$
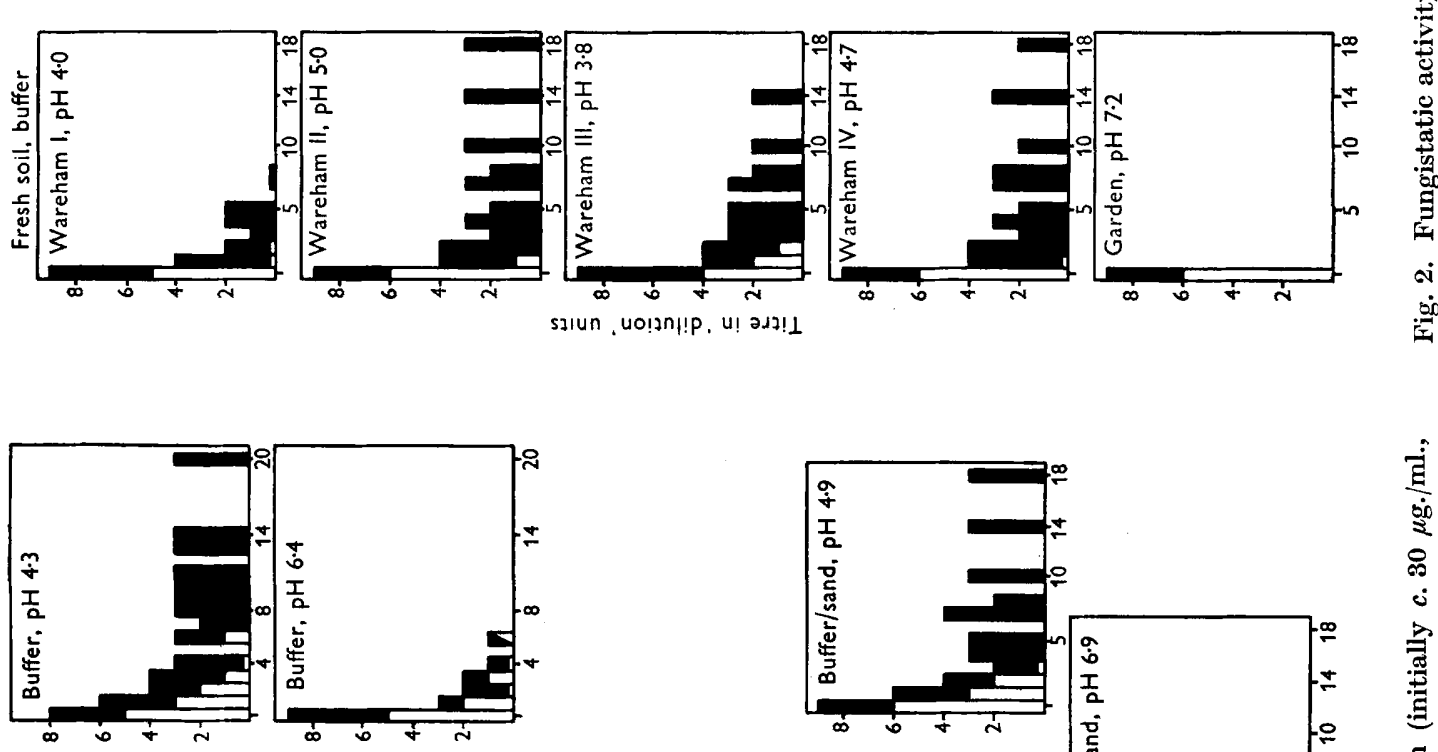

ह่

sio

คำ
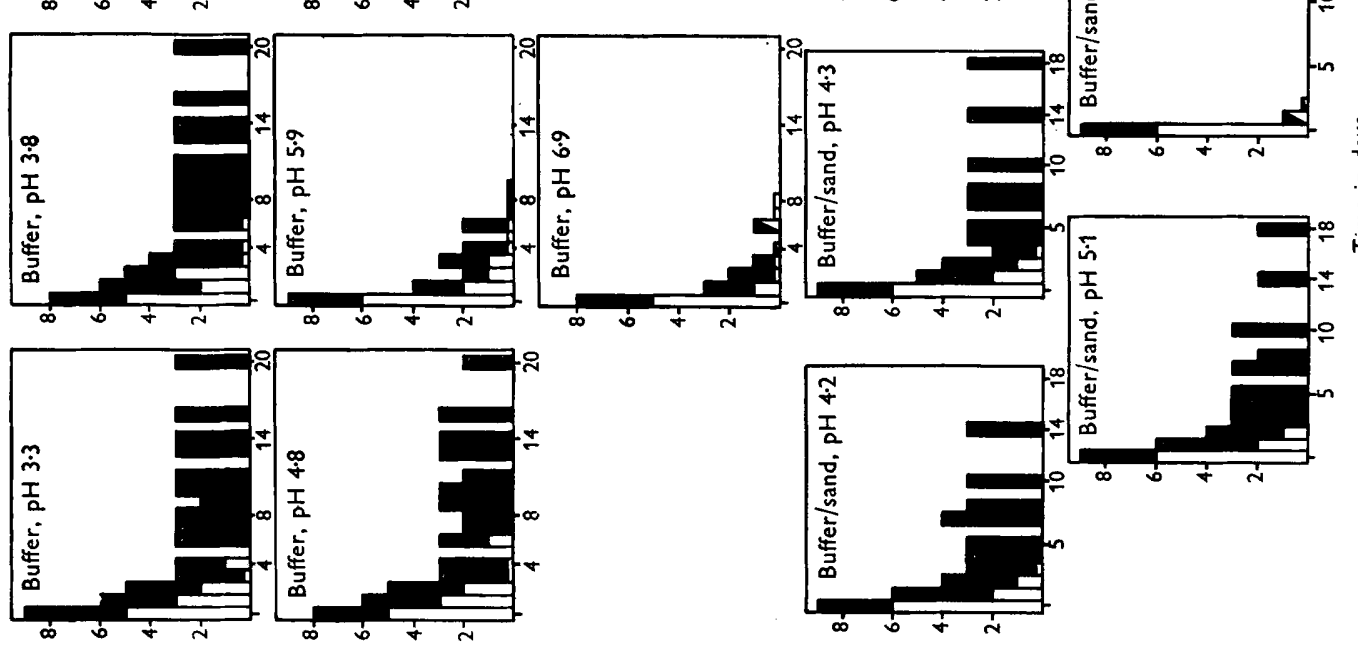

응

กั

을

क्ष

索i 

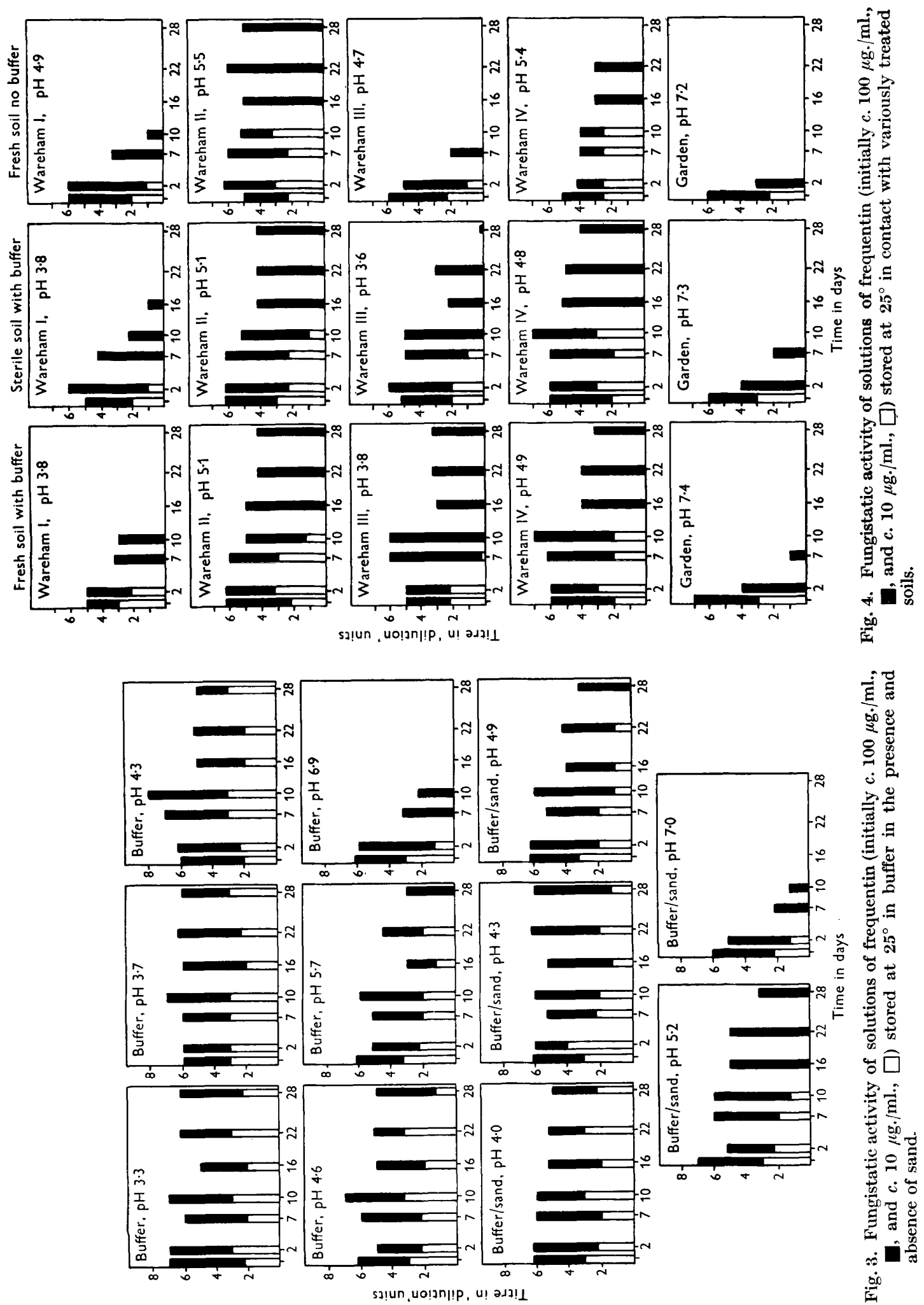

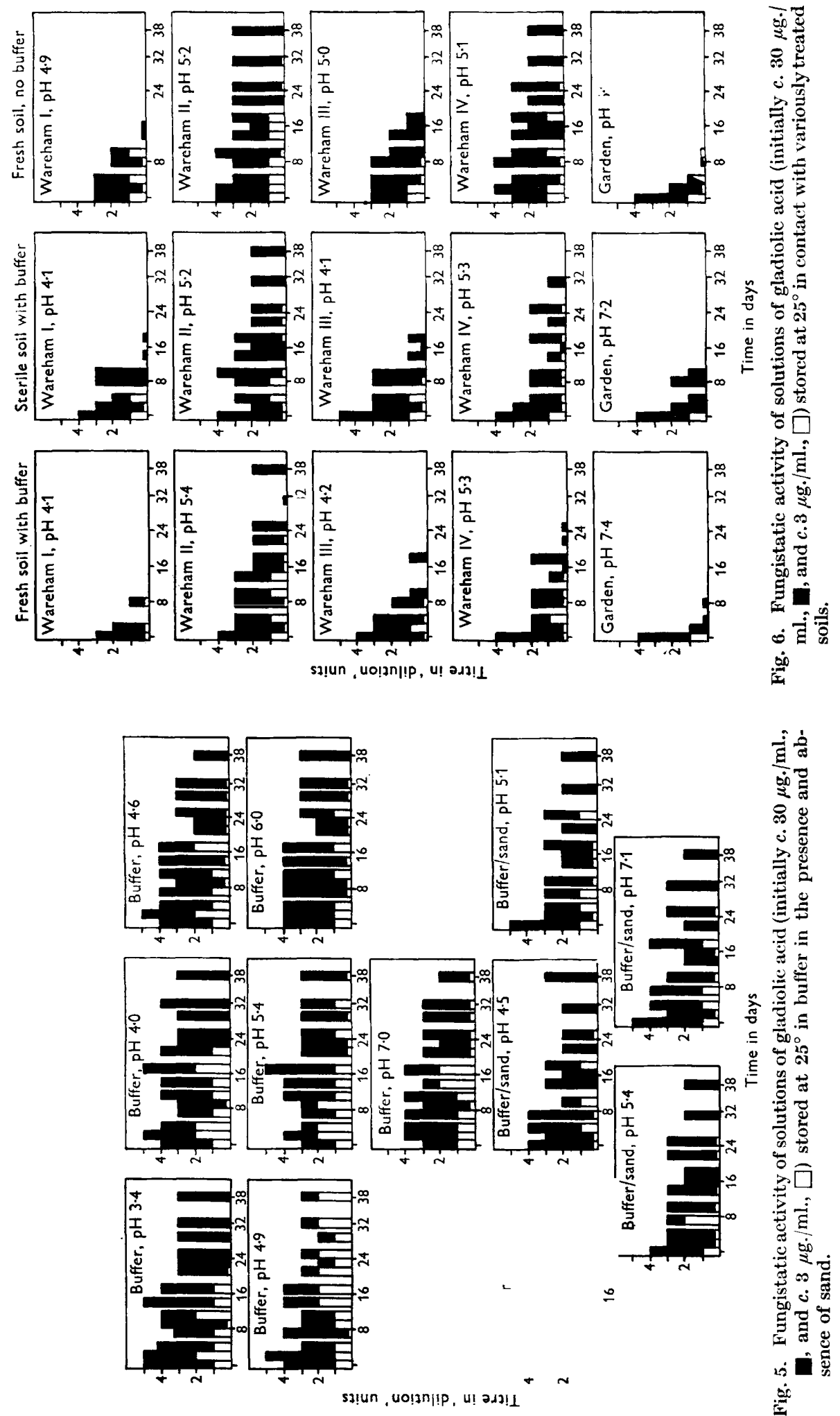

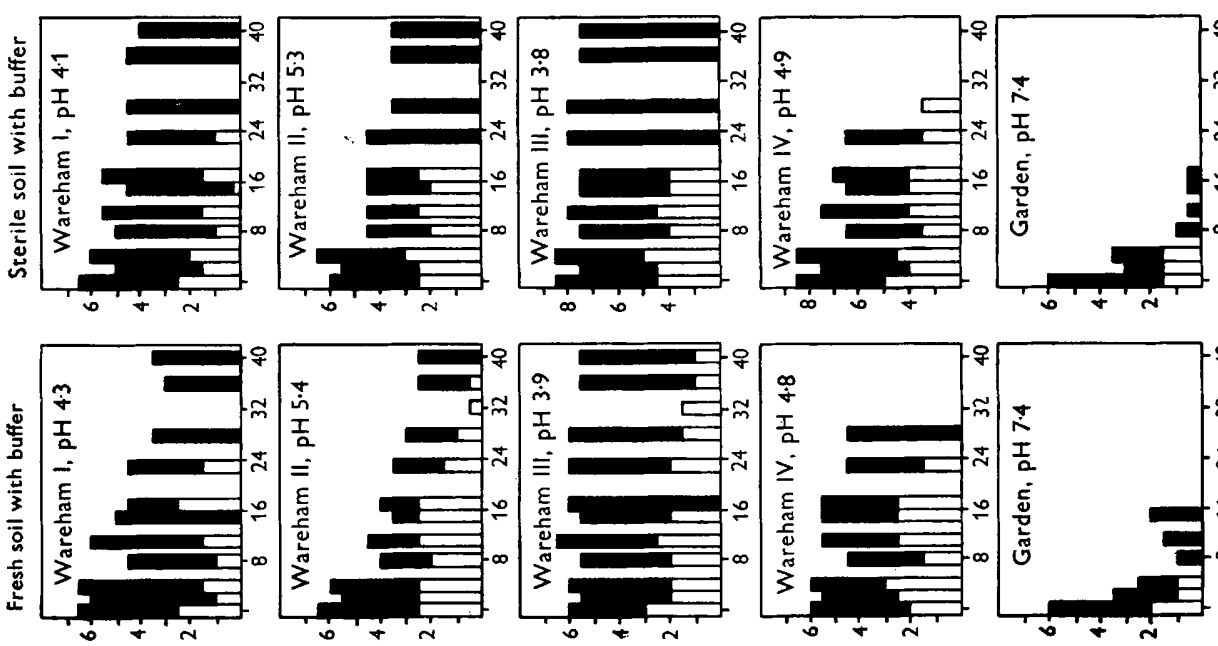

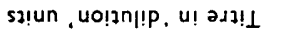

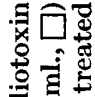

bo

त के है

늘 음

ن

爷

के

Sic
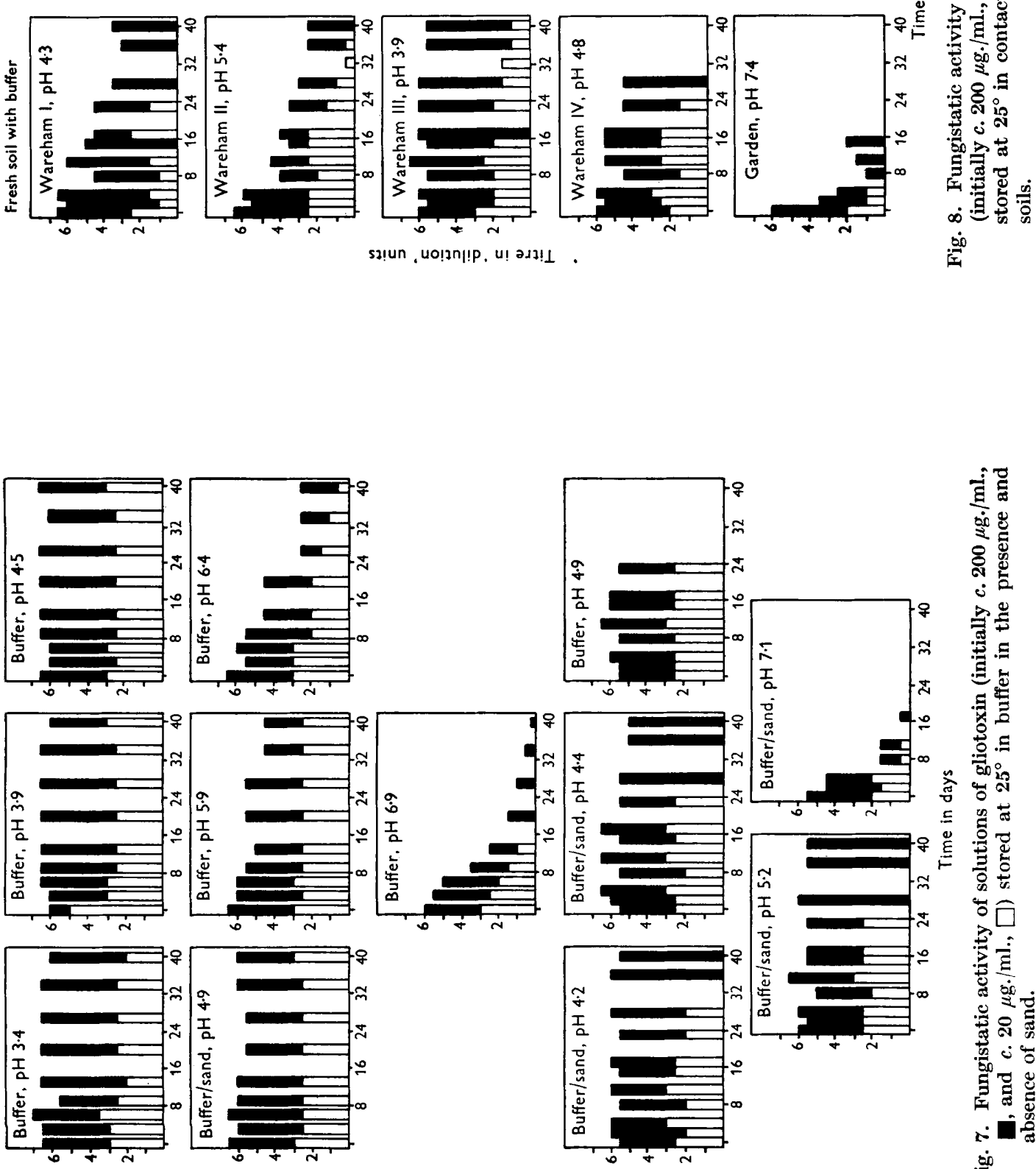

घี

in

8

ส․

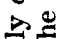

.

:

零

용. $30 \mathrm{in}$ क

总

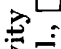

过

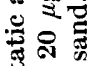

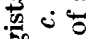

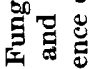

$\therefore$ 送

iो 

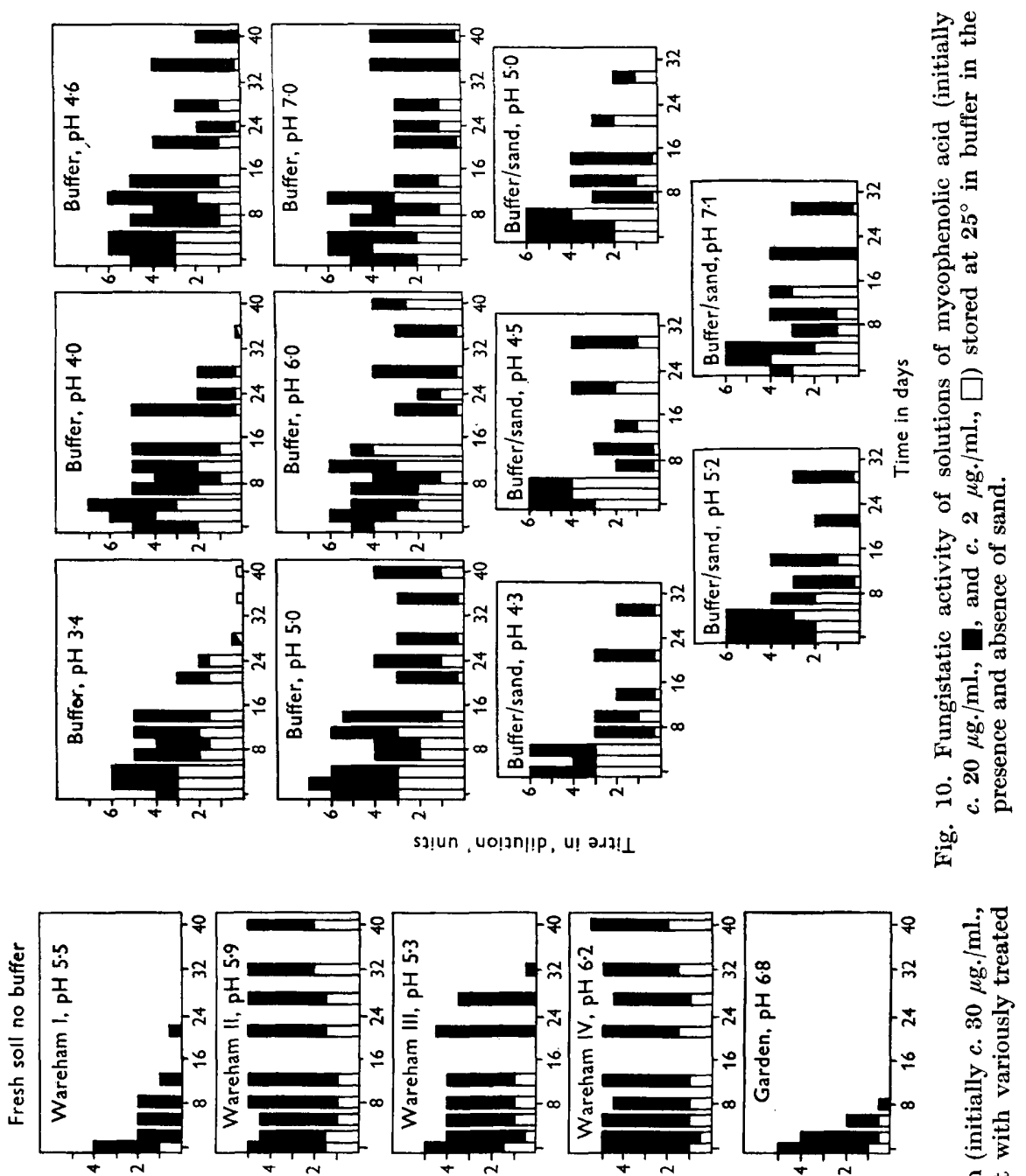

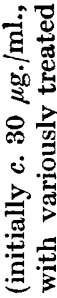
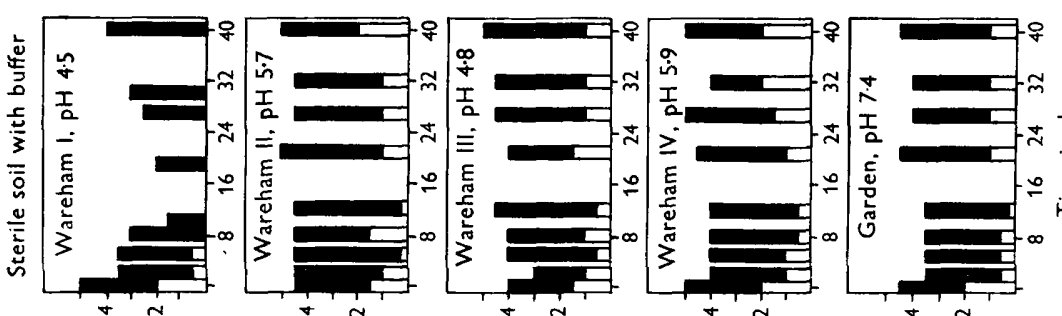

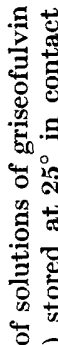
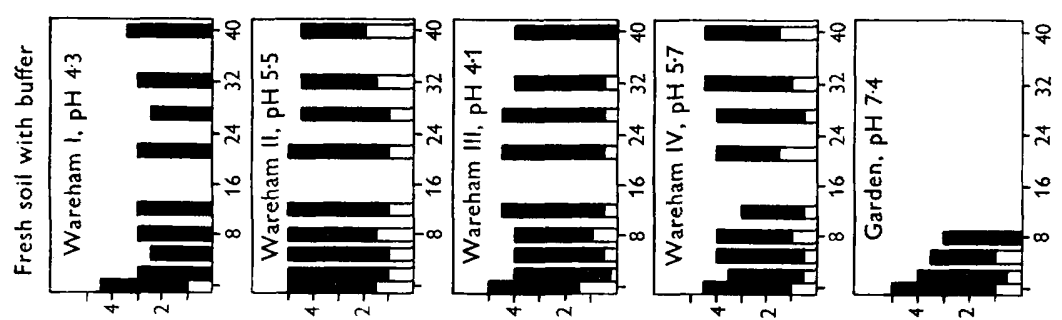

든

है

sł! un , uo!an!!P, U! 2ม?!। 

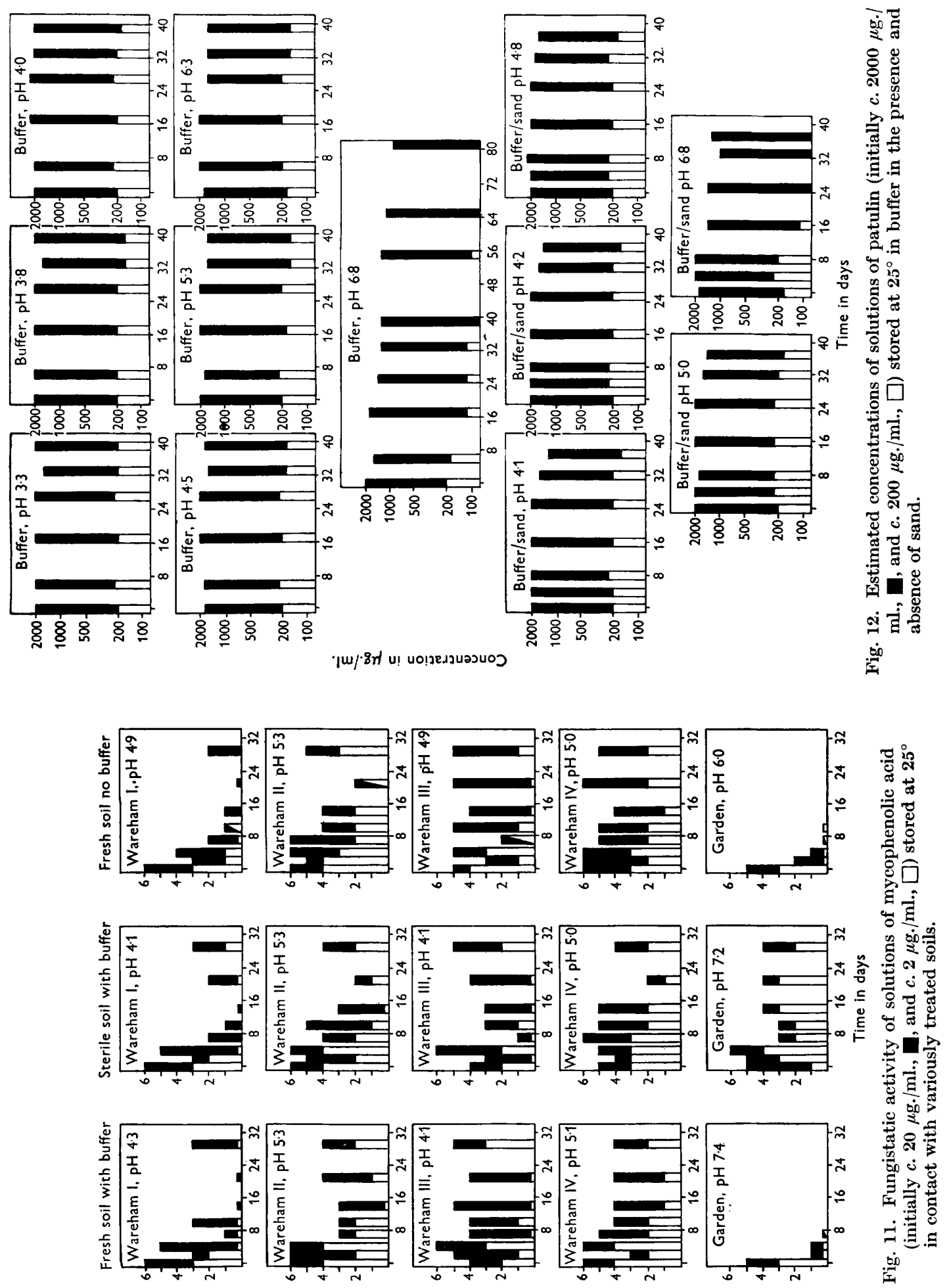

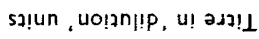



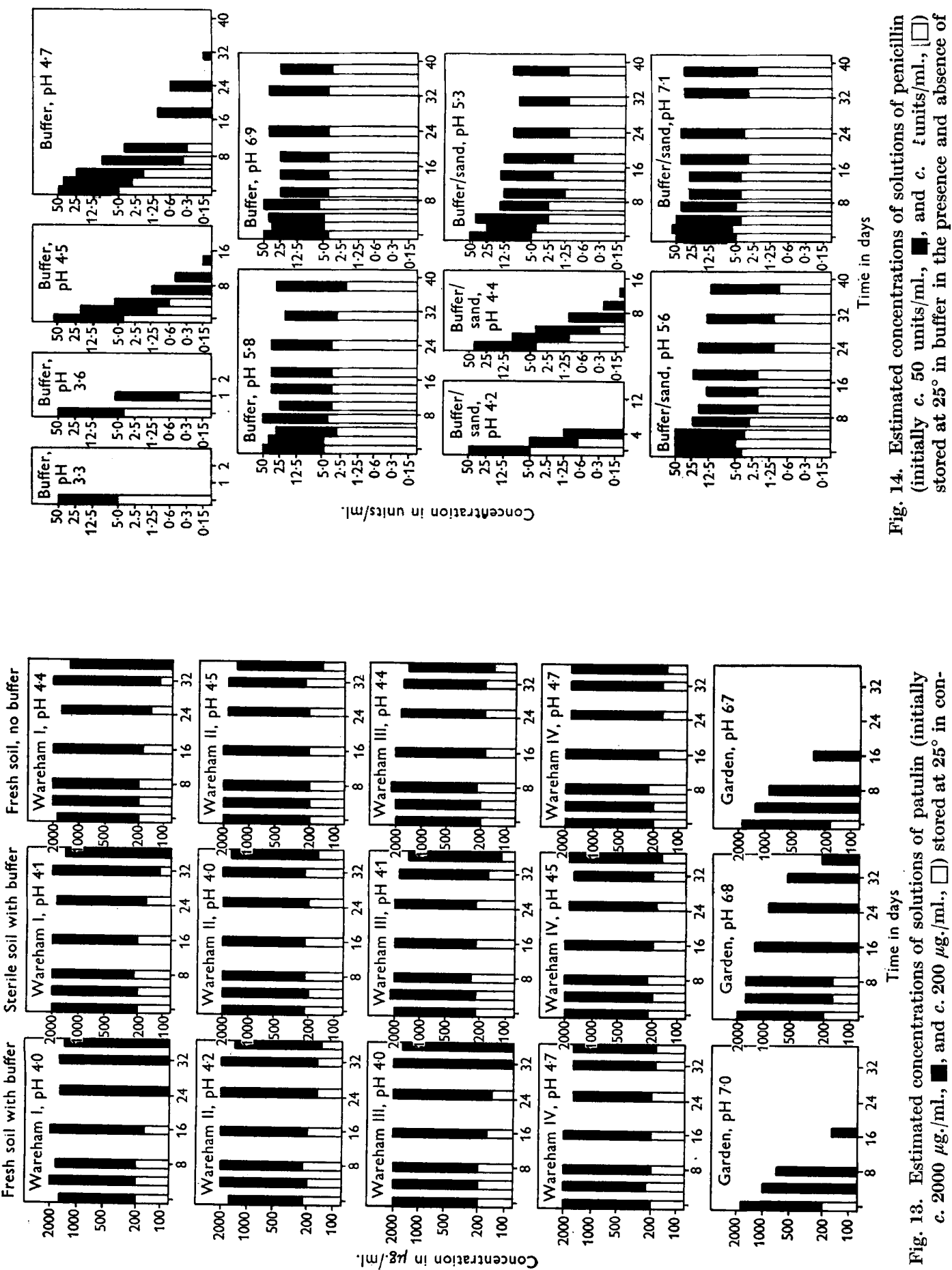

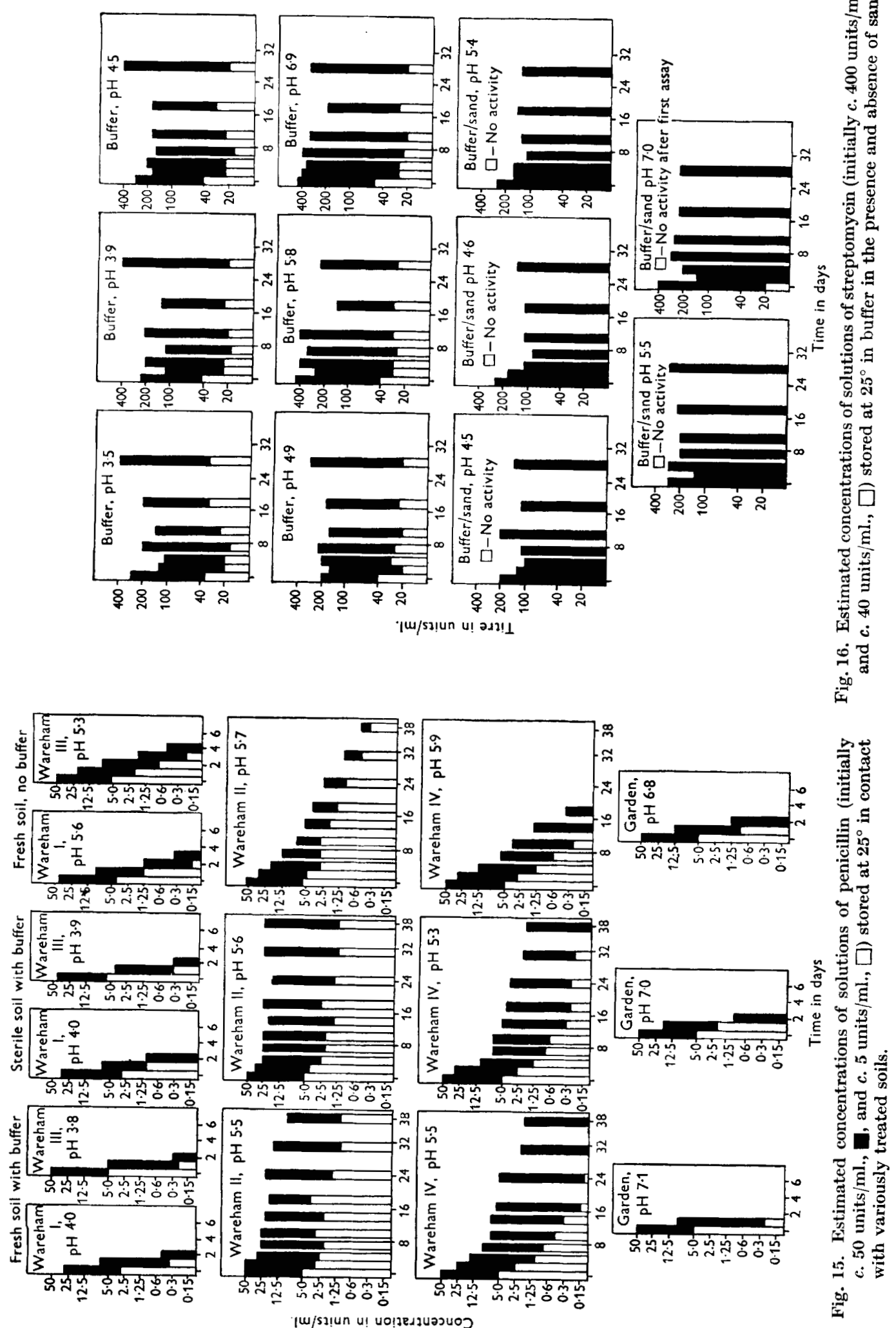

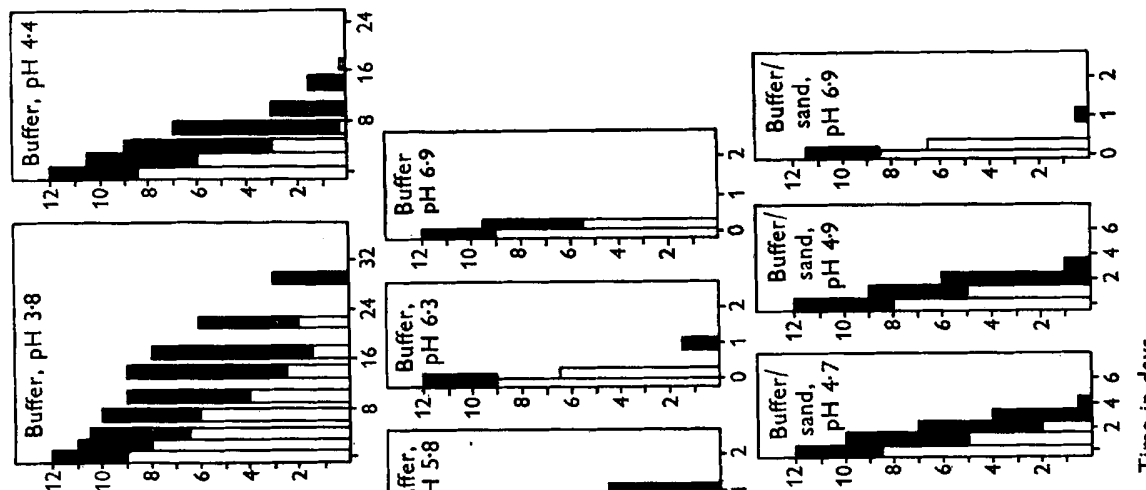

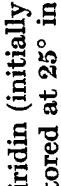

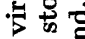
岁吕唯 究

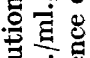

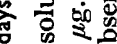
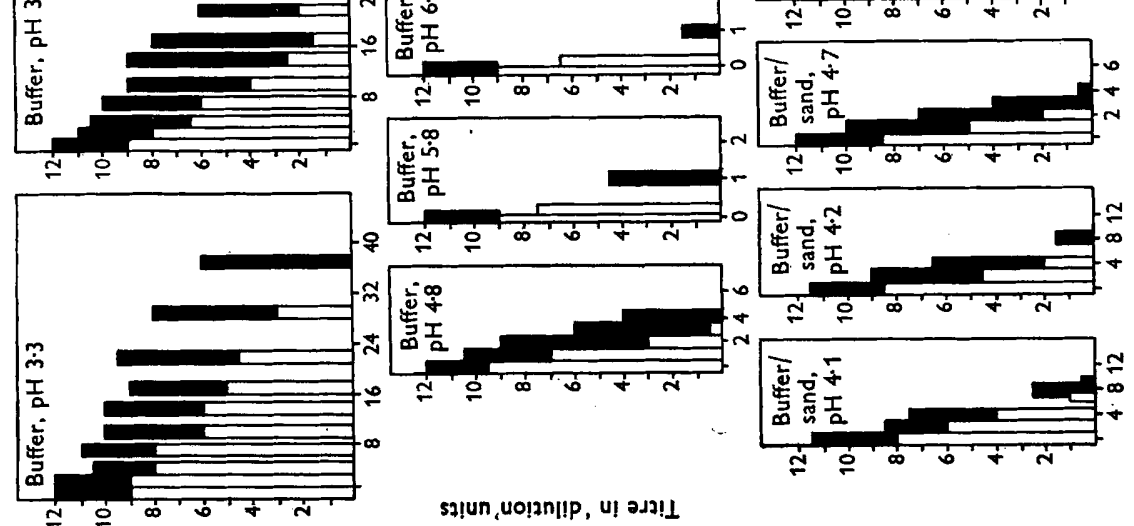
낭유 रें 踏 自密 ํํㄹ 氙 然通. 象总 $\stackrel{\circ}{\circ}$ 我

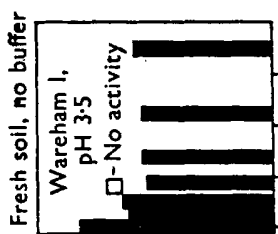

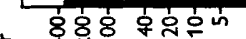

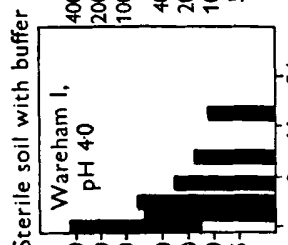

냉ㅇㅇㅇㅢ 훙ㅇㅇㅁ

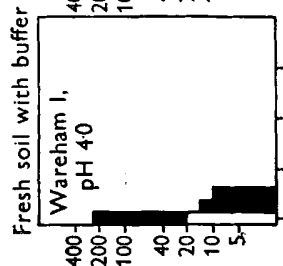

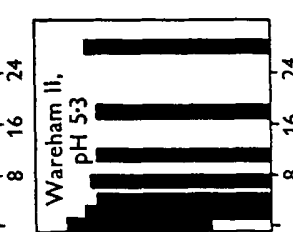

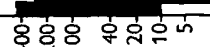

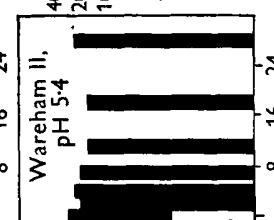

하융응ㅎㅇㅇㅇㅁ

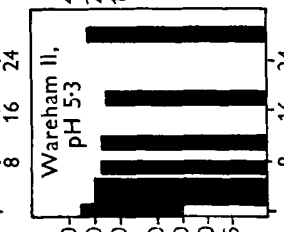

웅ㅇㅇ웅유어

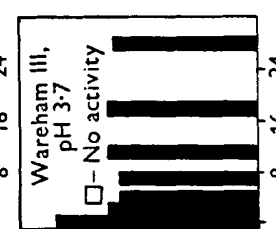

웅ㅇㅇ워음

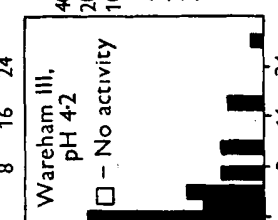

웅ㅇㅇ웅우의

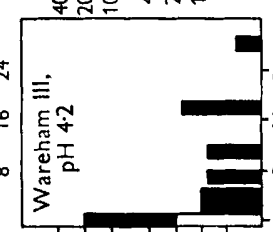

앙ㅇㅇ 웅의

ju/ss!un u! 2גנ!
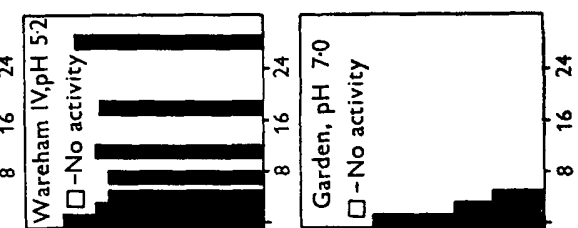

웅ㅇㅇ영혀은

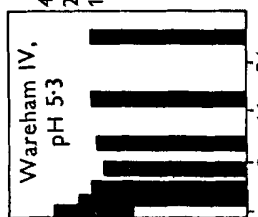

웅우웅ㅇ́

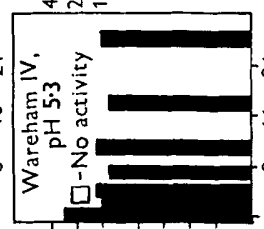

항ㅇㅁ응 후은

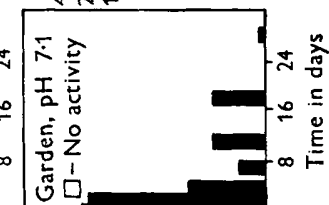

후융으 웅으느

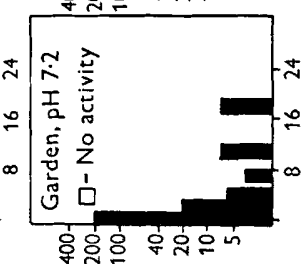

후융웅유음 


\section{Griseofulvin}

Solutions of griseofulvin were completely stable over the range $\mathrm{pH}$ 3:4-7.0 and addition of sand had no effect, and accordingly detailed data are not presented. Rapid biological inactivation occurred in the fresh garden soil (Fig. 9). It was stable in Wareham II and IV soils; it was also stable in Wareham III, though in the solutions in water an inexplicable rapid loss in activity took place towards the end of the experiment. In Wareham I soil the more

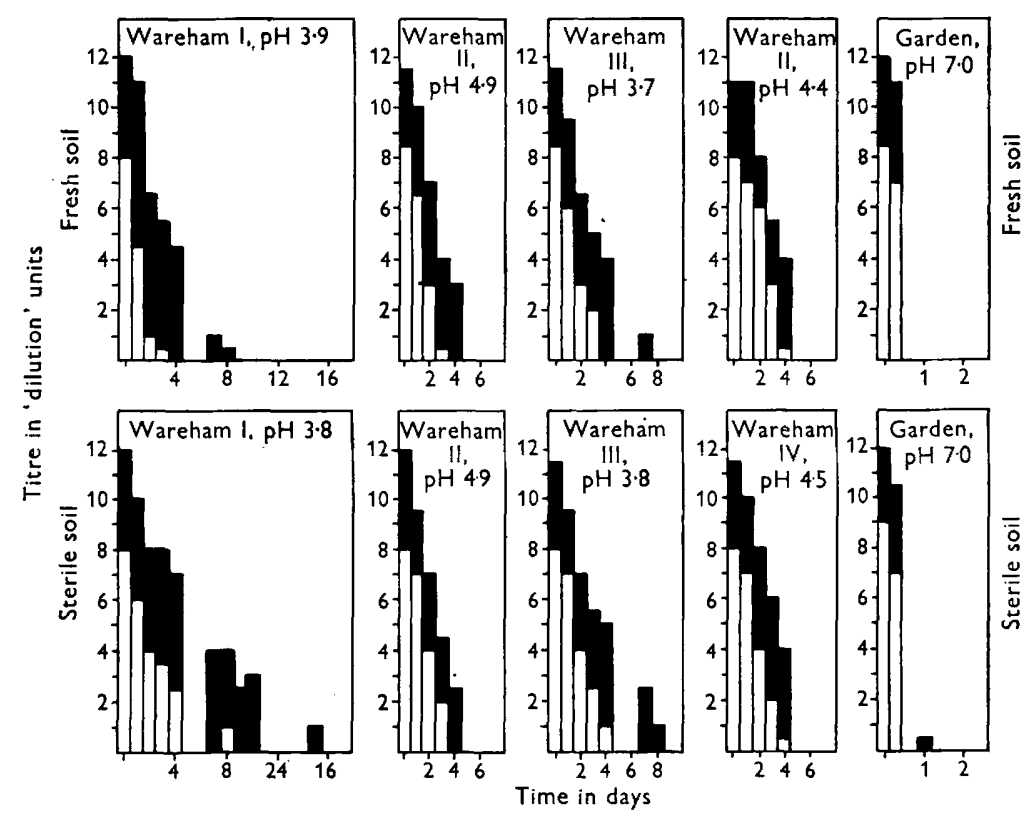

Fig. 19. Fungistatic activity of solutions of viridin (initially c. $100 \mu \mathrm{g} . / \mathrm{ml} ., \square$, and $c .10 \mu \mathrm{g} . / \mathrm{ml} ., \square)$ stored at $25^{\circ}$ in contact with variously treated soils.

concentrated solutions in buffer showed no indication of biological inactivation, and quite high titres were recorded after 40 days; however, the rather lower general level of activity as compared with that rccorded in buffer solution with no soil present, contrasted with the rapid and complete disappearance of griseofulvin from the less concentrated solutions, suggests that some such process as a physical adsorption took place.

\section{Mycophenolic acid}

Mycophenolic acid solutions in buffer at $\mathrm{pH} \mathbf{4 \cdot 6 - 7 \cdot 0}$ are only very slowly inactivated; at $\mathrm{pH} 4 \cdot 0$ and below inactivation is rather more rapid (Fig. 10). Sand had no effect. The antibiotic was very stable in Wareham II, III and IV soils (Fig. 11). In the Wareham I soil, whether fresh or partially sterile, activity gradually disappeared over 16 days and thereafter began to reappear. In fresh garden soil rapid biological inactivation took place. 


\section{Patulin}

Patulin was almost completely stable in buffer solution in the $\mathrm{pH}$ range 3.3-6.3; at $\mathrm{pH} 6 \cdot 8$ slow inactivation took place (Fig. 12). Sand had no appreciable effect on the rate of inactivation. It was very stable in all soils of the Wareham series (Fig. 13). Inactivation was more rapid in partially sterile garden soil and was greatly accelerated in fresh garden soil, indicating a considerable biological element among the factors causing inactivation.

\section{Penicillin}

Penicillin is stable at neutrality but decreases in stability as the $\mathrm{pH}$ is lowered (Fig. 14). This accords with previously published data (Florey, Chain, Heatley, Jennings, Sanders, Abraham \& Florey, 1949), though it was rather more stable at $\mathrm{pH} 5.8$ and 6.9 in our experiments than would have been expected from the earlier data. Sand had no effect on the rate of inactivation. The garden soil, whether fresh or partially sterile, rapidly inactivated penicillin, in spite of a $\mathrm{pH}$ favourable to stability. Inactivation was rapid in Wareham I and III, as would have been expected from the low pH. In Wareham II and IV it was surprisingly stable with but the slightest indication of biological inactivation (Fig. 15).

\section{Streptomycin}

Over the pH range $3 \cdot 5-6 \cdot 9$, no activity was lost from buffer solutions of streptomycin over the period of the experiment (Fig. 16). This agrees with results quoted by Waksman (1949). Addition of sand to the less concentrated streptomycin solutions (40 units $/ \mathrm{ml}$.) caused an immediate and complete loss of activity. At the lower $\mathrm{pH}$ levels it caused an immediate reduction in the activity of the more concentrated solution. This result is best explained by some form of adsorption. Siminoff \& Gottlieb (1951) have shown that streptomycin is bound by clay minerals; apparently carefully washed sand is also sufficiently acidic to bind the streptomycin anion. This adsorption appears to be most marked in acid solutions.

Streptomycin was also adsorbed on all the soils (Fig. 17), and this resulted in immediate and complete inactivation of the 40 units $/ \mathrm{ml}$. solution. In Wareham II and IV, once the adsorptive capacity of the soil was saturated, no further loss of activity took place. In the remaining soils the rate of inactivation, after the initial adsorption, was influenced by the presence of buffer. In Wareham I, streptomycin in water solution was inactivated slowly in sterile soil, rapidly in fresh soil; inactivation did not occur in fresh soil in buffer solution. A similar result was obtained in Wareham III, though here water solutions in fresh and partially sterile soils were inactivated equally rapidly. Inactivation was very rapid in garden soil, whether fresh or partially sterile.

\section{Viridin}

In buffer at $\mathrm{pH} 3.3$ viridin (Fig. 18) is moderately stable; above $\mathrm{pH} \mathbf{5 \cdot 0}$ it is very rapidly inactivated. Detailed study of the data will show that in all cases inactivation follows a course equivalent to a first-order reaction and 
that the rate is directly related to the $\mathrm{pH}$. Sand increases the rate of inactivation throughout the $\mathrm{pH}$ range tested. The stability of viridin in soil (Fig. 19) is primarily dependent on the $\mathrm{pH}$ of the soil. Inactivation is rapid in the neutral garden soil. Wareham II and IV accelerate inactivation to the same extent as sand; Wareham III has a rather more pronounced accelerating effect. In none of these soils is there any sign of biological inactivation. In fresh Wareham I soil, on the other hand, inactivation is much more rapid than in the same soil partially sterilized, in which inactivation is at the same rate as in sand.

\section{CONCLUSIONS}

These results show that the inactivation of antibiotics in soil may be the result of one or more distinct processes. These include: inactivation resulting from intrinsic instability of the antibiotic at the $\mathrm{pH}$ of the soil; inactivation as the result of microbiological activity; adsorption on some soil constituent, of which the clay colloids and humus particles are probably of greatest importance; some other kind of inactivation, probably chemical in nature, at present imperfectly understood.

The effect of soil $\mathrm{pH}$ on the rate of inactivation was most noticeable with the antibiotics albidin, frequentin, gliotoxin, penicillin and viridin.

Biological inactivation, expressed by more rapid inactivation in fresh than in partially sterile soil, occurred only in garden soil, Wareham I and Wareham III. These are the soils with the highest organic matter content and the most abundant microflora. Biological inactivation was most notable with the antibiotics griseofulvin, mycophenolic acid and patulin, but it was a contributory factor to the inactivation of several others.

Adsorption was an important factor in the inactivation of streptomycin solutions; it is noteworthy that carefully washed sand was capable of binding significant amounts of this basic antibiotic. The amount adsorbed was related to the $\mathrm{pH}$ of the solution. Adsorption was a less important factor in the inactivation of the acidic or neutral fungal antibiotics.

The rapid inactivation of gladiolic acid, penicillin and streptomycin in partially sterile garden soil, and some other similar observations, under $\mathrm{pH}$ conditions favourable to stability, suggests strongly that some other form of inactivation may occur. It is conceivable that the antibiotic in such cases is reacting chemically with a soil constituent, or that some soil constituent acts as a catalyst.

Finally, it may be noted that those antibiotics produced by fungi isolated from the acid Bagshot Sand soils were more stable in the acid Wareham series of soils than in the neutral garden soil. While no direct evidence is presented here that any of these antibiotics are produced naturally in soil, at least it may be said that all show a sufficient degree of stability, in some of the soils at least, for them to have a significant biological effect if produced.

My sincere thanks are due to Mr H. G. Hemming and his staff, for carrying out the large number of biological assays involved in this work, and to Boots Pure Drug Co. Ltd. for the gift of streptomycin. 


\section{REFERENCES}

Brian, P. W. (1946). Production of gliotoxin by Penicillium terlikoroskii Zal. Trans. Brit. mycol. Soc. 29, 211.

Brian, P. W., Curtis, P. J. \& Hemming, H. G. (1946). A substance causing abnormal development of fungal hyphae produced by Penicillium janczerwskii Zal. Part I. Trans. Brit. mycol. Soc. 29, 173.

Brian, P. W., Curtis, P. J. \& Hemming, H. G. (1948). Gladiolic acid, an antibiotic produced by Penicillium gladioli McCull \& Thom. J. gen. Microbiol. 2, 341.

Brian, P. W. \& Hemming, H. G. (1945). Gliotoxin, a fungistatic metabolic product of Trichoderma viride. Ann. appl. Biol. 32, 214.

Brian, P. W., Hemming, H. G. \& McGowan, J. C. (1945). Origin of a toxicity to mycorrhiza in Wareham Heath soil. Nature, Lond. 155, 637.

Brian, P. W. \& McGowan, J. C. (1945). Viridin: a highly fungistatic substance produced by Trichoderma viride. Nature, Lond. 156, 144.

Curtis, P. J. \& Grove, J. F. (1947). A fungistatic and bacteriostatic red pigment produced by a strain of the Penicillium nigricans janczerwskii series. Nature, Lond. 160, 574.

Curtis, P. J., Hemming, H. G. \& Sмiтh, W. K. (1951). Frequentin, an antibiotic produced by Penicillium frequentans Westling. Nature, Lond. 167, 557.

Florey, H. W., Chain, E., Heatley, N. G., Jennings, M. A., Sanders, A. G., Abraham, E. P. \& Florey, M. E. (1949). Antibiotics. Oxford University Press.

Foster, J. W. \& Woodruff, H. B. (1944). Microbiological aspects of penicillin. VI. Procedure for cup assay for penicillin. J. Bact. 47, 43.

Jefferys, E. G. \& Smith, W. K. (1951). A new type of soil pereolator. Proc. Soc. appl. Bact. 14, 169.

Pramer, D. \& Starkey, R. L. (1951). Decomposition of streptomycin. Science, $113,127$.

Rayner, M. C. (1945). Origin of toxicity to fungi in Wareham Heath soil. Nature, Lond. 156, 174.

Siminoff, P. \& Gotrlieb, D. (1951). The production and role of antibiotics in the soil. I. The fate of streptomycin. Phytopathology, 41, 420.

Waksman, S. A. (1949). Streptomycin, Nature and Practical Applications. London: Baillière, Tindall and Cox.

(Received 28 March 1952) 